\title{
Graphics Communication an Appraisal of an Art of Learning in Contemporary Nigerian Education
}

\author{
Emmanuel Bankole Oladumiyte \\ Department of Industrial Design, School of Environmental Technology, Federal University of Technology, \\ Akure, Nigeria \\ Email: eoladumiye@gmail.com
}

Received 15 May 2014; revised 17 June 2014; accepted 25 July 2014

Copyright (C) 2014 by author and Scientific Research Publishing Inc.

This work is licensed under the Creative Commons Attribution International License (CC BY). http://creativecommons.org/licenses/by/4.0/

c) (i) Open Access

\begin{abstract}
The concept of communication graphics is characterized by the technology that is infused with information and communication technology which cover any product that stores, retrieves, manipulates, transmits or receive information that helps in disseminating knowledge through graphic device visuals. That generates interest which is the key note to instruction, motivation, stimulation and ultimate finding relevance through the provision of changing experiences in knowledge disseminating. It is a genetic term that incorporates many professional fields of wide spectrum which ranges from product designs that communicate with various forms of electronic gadgets and tools from the information and communication technology sector such as project computer, television channels and other emerging media that allows organization to share information in learning process. The study highlights the historical background of graphic communication and the appraisal of graphic design communication in contemporary Nigeria. It discusses the role that communication plays in Nigerian contemporary education. It goes further to discuss the issues in graphic communication as regards to art of learning and finally concludes with the efficacy of graphic communication in contemporary Nigerian education.
\end{abstract}

\section{Keywords}

Graphics, Communication, Contemporary, Learning, Visuals, Education, Art

\section{Introduction}

Graphic design and communicating graphics function in contemporary Nigerian education as ideas and systems 
in which learning dissemination takes place. Graphics design and communication serve as pitch and marrow of any meaningful learning, because where there is effective communication, effective learning takes place. Educational service for schools such as the educational resource centers which provide graphic communication materials facilitates the implementation of educational planning and objectives thus promoting the efficiency of educational system in learning dissemination. Through this, educational programmes are developed and improved while teaching is enhanced and competence is improved. This is to say that Graphic Communication's (GC) presence and usage brought changes in communicative behaviour and above all in learning dissemination. There are various ways on how communication graphics can be realised in learning and in various formal and informal learning environment. Communication graphics in learning disseminate and education serve as a tool to support contemporary subjects. One can say that with the present technology, the students expect their learning environment to include technological innovation through the use of graphic media in impacting knowledge.

Graphics and communication as concepts incorporate many professional fields of wide spectrum. This field of spectrum ranges from various electronic gadgets that deal with something to communicate. Graphic is an adaptation from the Greek word "graphos" meaning: to write graphically and to draw out of art forms, either for illustration message or communication. It can also be defined as fine and applied art including visual arts that involves the application of lines and strokes to a two dimensional surface. It is the reproduction made from blocks, plates or types such as engravings, etchings, woodcuts and lithographs (Adelabu \& Idowu, 2011). Communicating graphics in reference to this study refer to arts or design and science in which ideas are expressed and communicated to viewers and learners through the use of diagrams, pictures, graphs, collages, posters and so on. These relate to the message sent and the sensitivity of the message received. No communication takes place unless the person receiving the message understands it. Generally, before graphics communication can be meaningful and effective, it must first be changed into some form of verbal or visual symbols or stimulus. These symbolic messages may then be transmitted through some channels or media through which someone else could notice the message and interpret it according to his previous experiences.

The use of Graphic communication is not limited to classroom alone, it is used as symbols for pedestrians according to Oladumiye (2005). Graphic communication visuals are signs and symbols that always involve the substitution of visual signs which has its root in visual road communication and it is used to settle traffic road congestion. Graphic communication in Nigerian Contemporary Education is a communicative device which focuses on the use of symbols, tracks, trademarks, international road symbols, maps, posters, bill-boards and handbills for learning process. Virtually all human beings obtained their awareness through graphic communication media.

\subsection{The Emergence of Graphic Design and Communication Graphics in Education}

Art historians and archaeologists revealed that the origin of formal graphic design and communication graphics dates as back as the 7th century AD when Pope Gregory used various art forms to teach in monasteries (Goldman et al., 1959). The history of art began beyond that period with the untutored but intensively felt drawing of early man. During this period, all arts are noted in nature based on variety of individual experiences. Both nature and personal experiences are of tremendous complexity and subjects to an infinite number of legitimate interpretations. Some pictures on walls and caves suggest that many prehistoric artefacts were the expressions of ancient metaphysical and mythical systems of ideas in which all kinds of needs were communicated and satisfied through graphics visuals.

Also, man in his domain has acquired the faculty of communication by speech; this was the biggest single factor in the success of homosapiens and also a great leap forward in the development of human communication which was later followed by the convention of writing and the perpetuation of knowledge which depends entirely upon memory. Later, according to Adamu (2005), men began to use visual communicative systems such as drawing, to represent concepts. Along the line, the American Indian developed picture writing that could be used to describe many activities. The Phoenicians introduced writing system by the use of symbols, "Aleph and Beth" to represent home, the head and neck of a camel were used as symbol for travel. The Greeks developed alphabets. They changed Phoenician symbols to suit their purposes; the Romans borrowed these basic symbols and redesigned the letters, thus giving the present appearance and sound accustomed to in those days contemporary education.

Printing is a great part of the record of graphic design and communication graphics. Printing encompasses and 
binds up with the development of letter forms and type faces. Block printing reached a very high standard by the year (1041-1049) during which Sheng, in China developed individual characters with hardened clay. In the thirteenth century, metal type printing system was used in the Far East, China, Korea, and Japan. In 1450, Gutenberg cast moveable metal types. The innovation by Gutenberg removed man from the dark ages of ignorance, thereby placing him in the first book in English at Bruges. In France, the first press was established between the year 1470 and 1720. It should be noted that Gutenberg, Morse, Marconi, Boll, Sheng, Caston and many others that were actively engaged in the printing process enriched the media stream of graphic designs and communication graphics in various ways by constantly developing and adding new devices to the already existing ones (Fatuyi, 2002).

\subsection{Appraisal of Graphic Design and Communication Graphic in the Art of Learning in Contemporary Nigerian Education}

There are traits of graphic communication in Nigerian contemporary education. The Nigerian culture e.g. Yoruba culture, Hausa culture, the Edos, and the Igbo traditions are full of graphical communications media: the traditional wall decorations, the traditional marks and various arts signs and designs. The graphical symbols and decorative patterns in the traditional Nigerian society, cave and wall painted for ritual purposes in shrines and theatres. Evidences of these communicative arts forms are inherent on the bronze, printmaking, terracotta, and stone carvings of many other cultures in Nigeria, the Igbo-Ukwu, the Nok, Ife Benin and Esie art and design were prominent centres for these artistic practices (Oladumiye, 2013).

Graphic design and communication graphics as an art of learning in contemporary Nigerian education undergoes a process of modelled in clay, plastic sine, sketched or drawn or painted on two dimensional surfaces prior to mechanical mass production. Contemporary graphic communication in Nigeria emanated as a result of the introduction of aesthetic education in the formal educational system. The development of graphic communication in Nigeria is therefore essentially the history of art education in formal school programmes. As a result, the world of information and communication technology has greatly influenced the teaching and practice of visual arts. The contemporary teaching and learning of graphic communication is aided by the use of some software such as CorelDraw, Adobe Illustrator, 3DS Max, and Photoshop. These have made it easier for graduates to express their creativity in advertising communication, book illustration, animation and photo editing, thus, conforming to the required skills of contemporary times (Okwoli, 2013). This can be seen in Figure 1, the poster of a cultural festival "Mare".

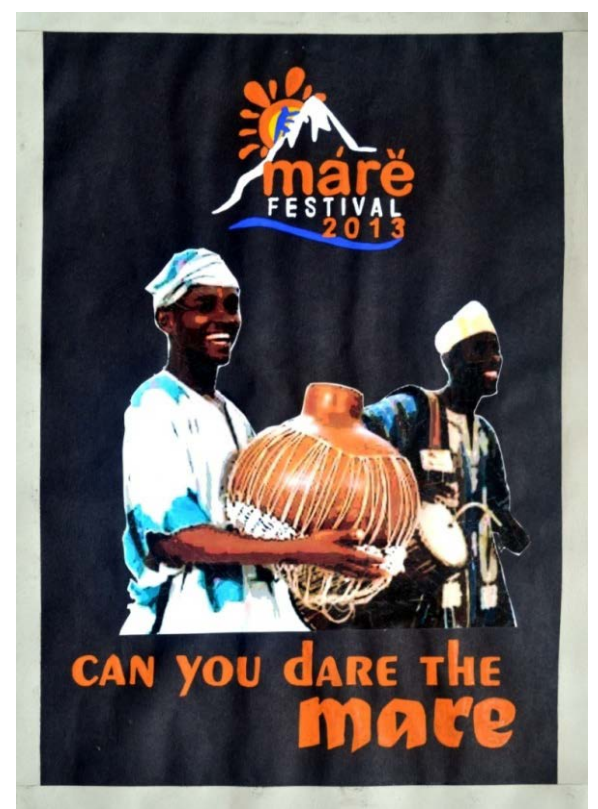

Figure 1. Poster on cultural festival mare. Source: Authors collection 2014. 


\subsection{The Role of Graphic Design and Communication Graphics in the Learning Process and Education Technology}

Education according to Fafunwa (1979), is the aggregate of all the processes by which a child develops the abilities, attitudes and other forms of behaviour which are of positive values to the society in which he lives. Philosophically, education is the process of personal development and it can be perceived as the transmission of culture through school. Psychologists emphasize that education is an art and science of human behaviour where scholars employ the scientific methods to learn how human beings develop and respond in various situations. This knowledge is applied to influence the behaviour of individuals and groups toward achieving desired goals (Akolo, 1986). Researchers have revealed that, with the introduction of print and its popularity through the introduction of printing press, dramatic effects have evolved on the lives and thinking styles of mankind. This is as a result of the fact that in print, information is abstracted from experience and organized in sentence by sentence order or hierarchal manner, while the visual media structure information about our experience of the world in a horizontal manner.

Graphic communication materials are useful as motivational visual aids in education and they are also the type of materials that teachers and students can easily create. The pictographic images, words and pictures, ideas and knowledge, are basic tools for learning. In order to interest students and other individuals, posters drawn, painted and, photographed should be enacted. Some of the posters should be serious, others should be relaxed and amusing while some may use many words, and others use scanty words. Figure 2 is an example of the above.

The role of graphic communication in education according to Mbahi (2005), designer of educational posters should choose those means that are most achieved. In the teaching learning and process, the emphasis is on the medium best suitable for students to learn. Teachers need to integrate graphic communicative visuals with appropriate teaching methods. This should be aimed at promoting challenging experiences in learners, colours that are both associated with the topic and pleasing to look should be chose. The decision to use drawings or photographs is the prerogative of the teachers. Leslie (2006) noted that teacher's autonomy over the nature of classroom interaction is the selection of learning activities and the pacing of instructions is generally recognized. He is of the view that these are important decisions to make, for it is of no use adopting something to teach in colours which are unpleasant. This relates to Kothari (2008) and the view of Terras (2013) who discovered that courseware packages are frequently developed in an artistic or pragmatic fashion without any systematic statement of the objectives or analysis of the learning tasks required this happens when the artists is merely asked to design or illustrate without being brought into the instructional design process. Graphic Communication in any

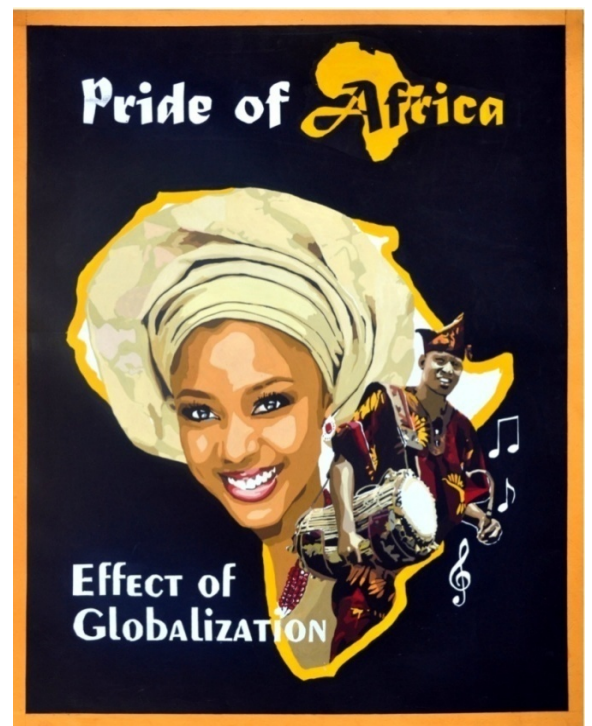

Figure 2. Effect of globalization. Source: Authors collection 2014 (Designed by Okoli 2013). 
design process requires finding out that the message is intended for, what the message is and what behavioural changes are expected as a result of the message. Graphic Communication is best suited to produce courseware based on the teacher's strategies. The courseware is assessed with learner's population as part of the formative evaluation to diagnose learning difficulties.

Educational Technology has come to mean different things to different people. Technology itself has developed as a scientific application concept in industrial world to the wide application and solution to all educational problems. Educational technologist, for instance Morrish (1975), states that the term educational technology, since it is relatively new, is in its nature elusive, it means different things to different people; to some, it is no more than a fashionable synonym for graphic audio-visual aids. To others, it has a wider connotation, implying an attempt to rationalize the whole structure of education and training in terms of improved methods of allocating and using both human and physical resources. He went further to say that to others, it carries a potential of mechanical features to be dreamed of and guarded against. This is an illustration of what the term educational technology is and why it cannot be separated from graphics art. As a result Oladumiye (2013), defines educational technology as a system by which graphical art illustration is being used to quickening and fastening the disseminating of knowledge to students and a means of enlightening the community as a whole about their immediate environment. That is to say, that educational technology is meant for instruction in the classroom situation also, it is meant for the enlightenment of the public through the use of the graphical illustration like bill boards, posters etc.

Reeves (1998) and Okwoli (2013), defines educational technology as a system of approach to instruction, incorporating specific measureable instructional objectives, diagnostic testing criteria for students' performance and the repeated redesign of the curriculum materials until the criteria are achieved. From all these and other perspectives, we can deduce that educational technology is the production of teaching and learning material through graphic design communication arts either for storage and retrieval and dissemination of information.

Educational technologists are

1) Creative artists who always look for combination of media and new teaching strategies in order to achieve a better learning and teaching process;

2) Graphic illustrators who are capable of achieving holistic designs which are generally efficient to the society and teaching learning process;

3) Keeper of visual records in learning process;

4) Those that communicate with graphic visuals and create awareness in learning process;

5) Those who add life to teaching and

6) Provide conducive learning environment with technology learning facilities that serves as tools to support traditional subjects and make use of new technology innovations like computer-based learning, materials.

\subsection{Issues in Graphics Communication as Regard to Art of Learning in Education}

Teachers have a duty to produce meaningful graphic visual messages which are of good quality and composition so that they can attract and hold attention to communicate. Pictures help to recall experience, aid detailed study, correct misconceptions build new experiences and give meaning to word symbols which may be used to determine a process, and may help in forming value judgement. A teacher who utilizes graphics in communicating can be a great asset to students and his teaching and instruction would be effective. Such teachers need to know the characteristics of both the student for he needs to focus on the needs of the students and how graphic design can help them to learn.

Bertoline (2005), notes that graphic communicative devices as applied by teachers in learning processes should be viewed as a universal approach to all school subjects. He also notes that most contemporary theories, both psychological and scientific concepts of teaching that exclude considerations to the use of graphic devices are inappropriate as a framework for curriculum design, for they could be too abstract or little related to students interest. Graphics Communication is a unique source of intellectual stimulus. It is an area in which observation and thinking skills have to be based on direct experience. Although approaches to appropriateness tend to be associated with certain assumptions about teachers, students and resources, Bertoline noted that what is important is the extent to which appropriateness must logically affect the teacher's preparation of graphic communicating devices.

Teacher's autonomy is a significant variable in the shaping of teacher's communicative devices. Sometimes 
there are no external directives to teachers on what kind of communicative visual devices they could prepare and utilize. Consequently, teachers may develop communicative visual materials in any way they think appropriate or even exclude the subject or topic from the curricula. In such cases, teachers have a great deal of autonomy in school-based decisions about the use of visuals in their teaching. Graphics Communication is an integrated process which involves people, procedures, ideas, devices and organization. It is an integral part of a teacher's aide. Researchers have also revealed that $75 \%$ of what we learn is through sight, $13 \%$ through hearing, $6 \%$ through touch, 3\% through taste and 3\% through smell. As a result, Graphic Communication is a vehicle of technology brought together with the media specialist to develop, design utilize and evaluate the instructional resource programme. In the learning process, teachers should encourage learners to be prepared to look carefully, and not just seeing that which is most obvious in a communicative medium. A good graphic illustration may not mean the same thing to everyone (Newick, 2001; Wikipedia, 2012).

\subsection{The Use of Graphic Communication as Instructional Materials for Effective Learning in Contemporary Nigerian Education}

The use of relevant materials would help the teacher's effort so that learning could be effective and efficient in his teaching. For instance, instructional materials will guide the thinking of the teacher when he wants to discuss concepts that are too abstract for the pupils' level. The teacher can therefore, use the needed materials to present the facts and information to his pupils (Figure 3 and Figure 4, the use of match sticks in designing objects stands as an example of the use of relevant materials). The power of visual communication is derived from the quality of presentations (Mbahi, 2005). Quality in the real sense is a totality of numerous specific elements over which designers have much control such as content, layout, arrangement selection, use of colour sketching lettering and choice of materials. The ultimate effectiveness of a visual presentation depends upon a mix of these elements plus the observers themselves and the conditions under which the images are seen. Whatever the purpose of a visual presentation is, whether it be for an overhead transparency, a colour slide for a program title, a handout for a lesson assignment or a chalkboard, white board, and display board, there are important questions to keep in mind.

- Is the meaning quickly clear to the viewers?

- Is the structured well laid out in a form that communicates in an effective way to the audience?

- Is the major idea differentiated from minor ones?

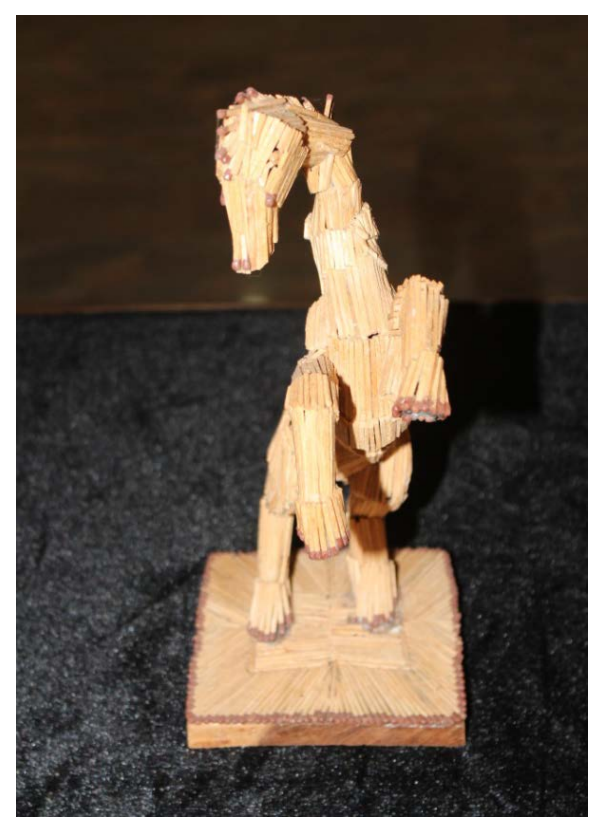

Figure 3. Matches sticks. Sources: Department of Fine and Applied Arts, Obafemi Awolowo University. 


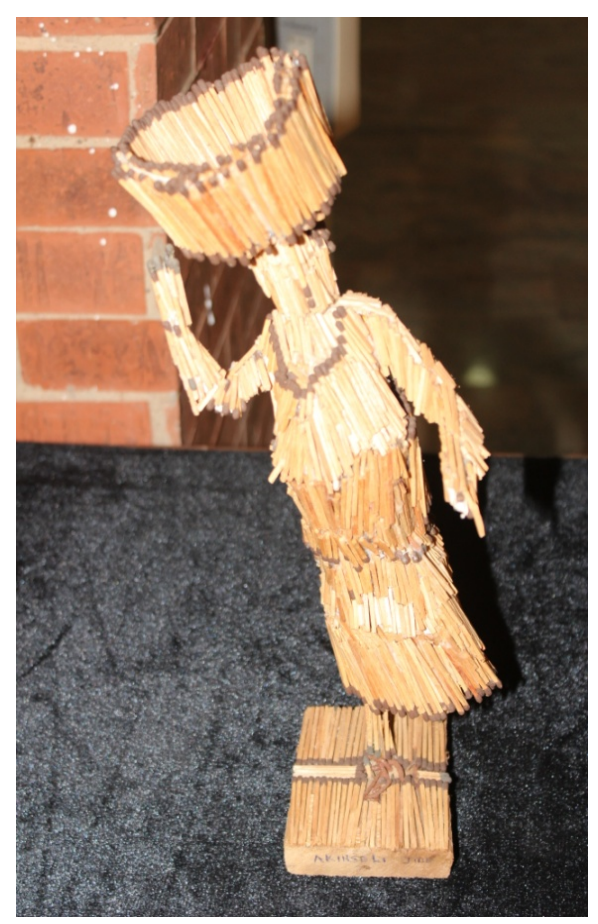

Figure 4. Match sticks. Sources: Department of Fine and Applied Arts, Obafemi Awolowo University.

- Is it pleasing in arrangement, style, colour and is it appropriate for the purpose it is designed for?

Several considerations are important in planning any display; these will have direct influence on the effectiveness of communication. The clarification of the key idea or theme for the display and determination of the desired viewers' action or reaction and with several Graphics design principles should be considered especially in order to achieve a maximum productivity in the learning process. The following are some of the major things to be considered: balance, shape, emphasis, contrast, the colour wheel, harmonious colour;

Balance: Could be in two ways: the formal and informal. The two may be used for a design, the content and purpose of the presentation will suggest which is appropriate. Students, however enjoy informal display for bulletin boards and exhibits. Figure four is an example of Balance picture for classroom teaching.

Shape: A configuration pattern is usually found in effective display. It may be established by the directions that are developed to guide the viewers to see details in proper sequence. Whether the shape is subtle or obvious, it must be present; it should be very evident in the original layout.

Emphasis: Through the proper use of lettering one or more dominants colours and directional a well designed layout will emphasize the central idea of the instructional material. Figure 5 and Figure 6 are on product advertisement pointing to Emphasis, Harmony, Colour and Contrast in designing a teaching aid

Contrast: For instance, for a part of displays to communicate they must be noticed. A skilful arrangement exhibit which contains contrasting areas of light and dark will catch the eye of the viewers. One way to achieve such contrast work is the use of dark papers as a background for mounting light pictures, or vice versa.

Harmony: A good layout of instructional materials should be harmonious. This means that all the elements (lettering, colour, materials) must work together to support the basic idea presented. No one element should distract or capture attention to the exclusion of others.

Colour: An important element in any successful educational technology instructional material is the element of colour harmony. Effects with colour can easily be achieved in many ways, felts pens, coloured pencils, coloured paper, a microcomputer with colour ability to use colour wisely requires some thought about why, where, when, it can and should be used. As a result colour wheel cone has to be considered, the harmonious colours, monochromatic, the analogous and complementary colours.

The monochromatic colours composed of the use of one colour tinted to many shades. 

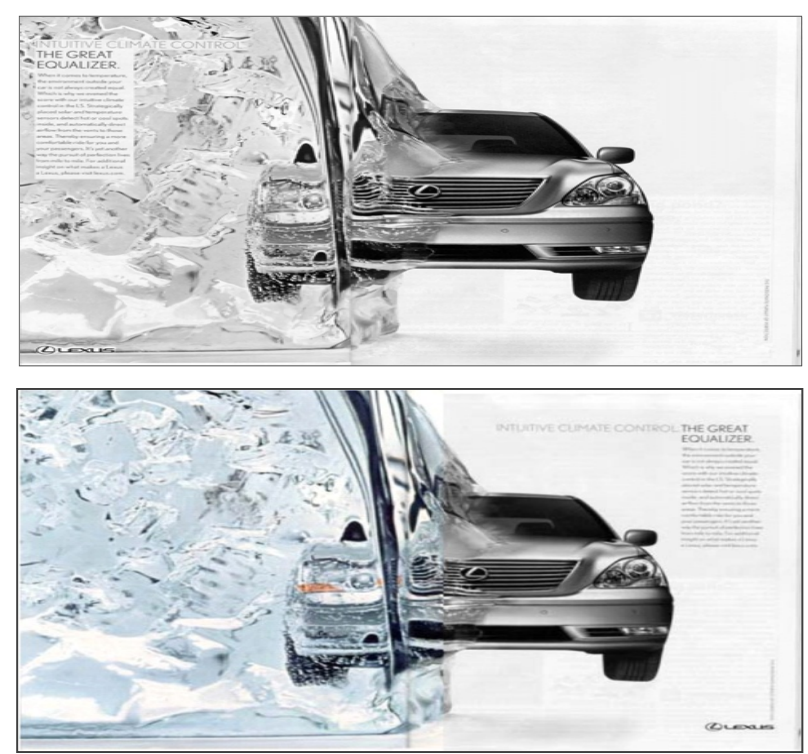

Figure 5. An example of balance picture poster of a car advert. Source: Authors collection 2014 (Photographed by Samuel).

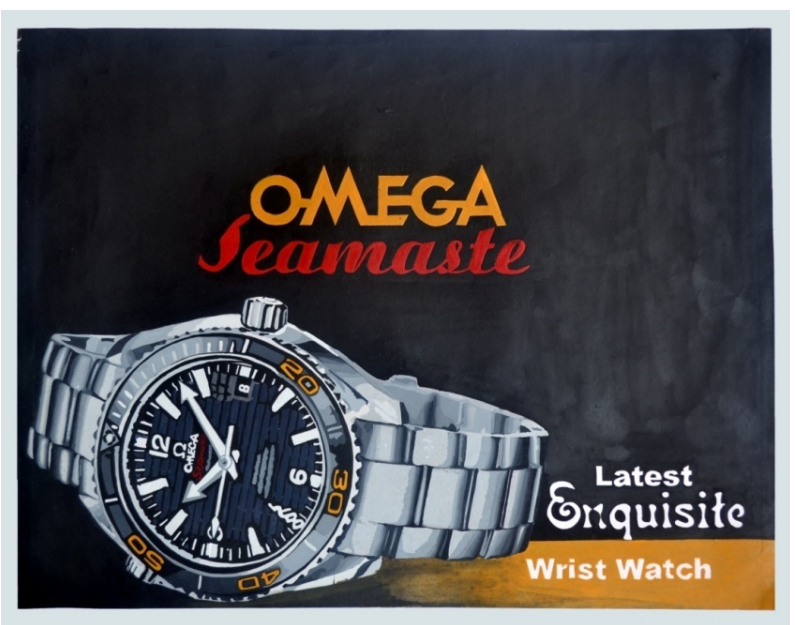

Figure 6. Omega wrist watch. Source: Authors collection 2014 (Design by Okoli 2013).

The complementary colours are colours opposite each other that complement each other for example yelloworange and blue-violet. Sometimes to create a harmonious effect, try to alter one colour slightly by adding white, black, or another colour.

- Here are some hints for using colours in producing instructional materials in graphic communication.

- Keep your colour designs simple.

- Limit the number of different colours used in a display.

- Use your colour to attract attention, give emphasis create contrasts create moods and guide viewing (Campbell, 1993).

On dark backgrounds for effective and powerful messages, use white, yellow, orange, green, red, blue or violet. On light or white backgrounds, use, red, orange, green, blue, violet, and among other things, in sketching and drawing many people begin to defend their inability to draw. All human beings are endowed with the sense of creativity which should be displayed by individuals. Another important requirement for creating effective productivity in education technology is legible lettering. The application of computer design has made things 
easy and simple in achieving good design in learning process. Computer design media are commercially produced, and many institutions use computer for local preparation of designs for many type of communication technological media (Maitland, 1951).

\subsection{The Efficacy of Graphic Communication in the Learning Process}

Research reveals that graphic communication in learning processes has the potential to increase students' learning system and it is better than teaching without the use of visual aids because the use of visuals enhance teaching. The teacher's instructional materials, in form of graphic design visuals, support and, improve students' outcome. Various comments based on experimental and research study approaches on the efficacy of graphic communication on the learning process suggest that students not only learn more when visuals are added to their teaching methods, their interaction satisfaction and awareness is improved. Visual aids through graphics communication carry details and relevant environmental information that relates to their areas of problems in which solutions are found.

Terras (2012), propounded that the efficacy of graphic communication visuals is a process that acted as information and it accelerates the learning process because they help students to master more subject matters and sharpen their learning skills in a shorter space of time. Kester (2007) identifies two sources of ideas: sensation and reflections. He stipulated that in the efficacy of graphic communication, visuals sensation conveys into the mind distinct perception of things while reflection is the perception of operation of minds, as a result, man thinks visually and the visual makes urban thinking possible, that is, talking without visuals for example, does not provide several linked options for learners, but visual presentation and talking have to go hand in hand.

Horn and Heather (2011) state that teachers' instructional practices are transformed by learning how to teach with graphic communication instructional materials because they develop new skills and build pedagogical strategies using technological visual aids. The research further reveals that $75 \%$ of the teachers said that teaching with graphic communication instructional materials has a positive impact on their system of disseminating knowledge in their classroom settings. Graphic communication devices generates interest which is a key note to instruction, motivation, stimulation and an intimate finding of relevance through the provision of charging experiences. In the efficacy of graphic communication, other researchers like Brown, Lewis, and Harderoad (2003) note that this concept is deeply involved in the actual process of perception, thought and bodily action. As a result, it is incumbent for the teacher to fill the students' environment with many different graphic visuals to stimulate their sense of awareness and make learning easy.

\section{Conclusion}

An attempt has been made in this study to highlight the roles of graphic communication in the dissemination of knowledge. It is an accepted fact that instructional methods through graphic communications visuals are an integral process which involves people, procedures, ideas, devices and organizations. Some researchers of educational technology opine that graphic communication is an integral part of learning process; they concluded that $75 \%$ of what we learn is through sight, $13 \%$ through hearing, $6 \%$ through touch, $3 \%$ through taste and $3 \%$ through smell. The above statement explains the role of graphic communication as a vehicle of technology that brought the teacher, the learner and the audience together with the media specialist to develop, design, utilize and evaluate the instructional programmes in contemporary Nigerian education. It is established in this study that pictures, posters, signs and symbols determine learning process and also educational system. The study highlighted the historical background of graphic communication and the appraisal of graphic design communication in contemporary Nigeria, here it discussed the role that communication plays in Nigerian contemporary education. It went further to discuss the issue in graphic communication as regard the art of learning and finally, the efficacy of graphic communication in contemporary Nigerian education in disseminating knowledge.

In conclusion, learning process and dissemination of knowledge is much better when approached by the use of graphic communication medium because the use of this concept in teaching and learning process increases perceptual range along with conceptual readiness. It also increases knowledge complexity of reasoning process and the closely allied types of intellectual judgement coupled with the preservation of the natural intensity of all modes of perception and sensation in learning. Graphic communication co-ordinates all of these and other various modes of perception and sensation with one another in relation to the environment and it increase the expression of thought in required form in contemporary Nigerian Education. 


\section{Recommendation}

Brown et al. (2013) noted that students’ bodies may be captivated in the classroom or learning environment. The extent to which their minds can assimilate new knowledge is based on the soundness of the communicative graphic medium and their field of experience. That is, graphic communication visuals used in the classroom teaching should focus on the understanding of the learners. Also, in preparation of graphic visuals, the illustration either in a painting, poster and drawing forms must be simple and straight to the point. Only images that contribute to the sentence structure are of vital consequence.

There should be visual and verbal relationship and simplicity of visual. Also the concept of the visuals provided should attract and be able to hold the attention of the students by the use of the principles and techniques of graphics, like colour, balance, unity, texture, line, contract harmony, proportion and perspective; and also the mastering of the principles of colours is essential e.g. the basic primary colour, the secondary, tertiary, analogous, complementary and harmonious colours.

\section{References}

Adamu, A. A. (2005). History of Class Room Art in Nigeria (pp. 103-110). Maduguri: King Well Publishers, Ltd.

Adelabu, O. S., \& Idowu, S. O. (2011). Pursuit of Industrial Design Career in Nigeria: An Appraisal of the Current Trend. Journal of Industrial Design, 1, 1-9.

Akolo, J. B. (1986). Graphics Communication in Education: A Paper Presented at the Professional Seminal on National Education Technology Centre (pp. 99-102). Kaduna: Ahmadu Bello University Press.

Bertoline, G. R. (2005). Fundamental of Graphic Communication (pp. 12-125). 4th Edition, New York: McGraw-Hill Companies, Inc.

Brown et al. (2013). A. V. Instruction; Technology and Media Methods. New York: Mc-Graw-Hill.

Brown, J. W., Lewis, R. B., \& Harcleroad, F. F. (2013). A. V. Instruction; Technology and Media Methods. New York: McGraw-Hall Book Company, Inc.

Campbell (1993). A Simple View of Colour. In A. Byme, \& D. Hilbert (Eds.), Readings on Colour (pp. 88-94). Cambridge, Mass: MIT Press.

Fatuyi, R. B. (2005). General Concepts Philosophy and Psychology of Industrial Design (pp. 13-20). Akur: BSIV Publishers.

Goldman, E. F., Lane, F. C., \& Hunt, E. M. (1959). The World’s History: New York Harcourt Brace (pp. 98-110). New York: World, Publishing House.

Horn, M. B., \& Heather, C. S. (2013). The Rise of K12 Blended Learning. Journal of the Association of Architectural Educators in Nigeria, 2, 29-32. http://wikipedia.org/wikieducationtechnologies

Kester, L. K. (2007). Designing Support to Facilitate Learning in Powerful Electronic Learning Environments Computers. Human Behaviour, 23, 1047-1054.

Kothari, C. R. (2008). Research Methodology, Methods and Techniques (2nd ed., pp. 109-110). New Delhi: New Age International (P) Limited.

Leslie, R. P. (2006). Education in the Arts. Journal of the Study of Education and Art, 68.

Maitland, G. (1951). The Art of Colour and Design. London: McGraw-Hill Book Company.

Mbahi, A. A. (2005). Art Teacher, Department of Creative Arts (pp. 77-82). Maiduguri: University of Maiduguri.

Morrish, I. (1975). Sociology of Education: An Introduction. London: George Allen and Unwin.

Newick, J. (2001). Study of the Context of Participation in the Arts. Journal of the Study of Education and Art, 68, 89-99.

Okwoli, F. I. K. (2013). A Blended Instructional Approach to Traditional Learning in Contemporary Higher Eductaion: A Paradigm Shift for 21st Century. Journal of the Association of Architectural Educators in Nigeria, 2, $29-32$.

Oladumiye, E. B. (2013). Towards Solving Traffic Problems Using Graphic Design Visuals in Multicultural Societies: A Case Study of Selected Cities in Southern Western Nigeria. Journal of Arts and Design Studies, 12, 58-66.

Oladumiye, E. B., Adiji, B. E., \& Olabiyi, A. T. (2013). Nigeria Museum and Art Preservation: Repository of Cultural Heritage. International Journal of the Inclusive Museum, 6, 93-95.

Oladumiye, E. B. (2005). An Historiological Perspective of the Nigerian Contemporary Printmaker. Journal of Issues and Challenges of Creativity, 2, 102-107.

Reeves, T. C. (1998). The Impact of Media and Technology in Schools. Journal of The Journal of Art and Design Education, 2, 58-63. 
Terras, M. R. (2012). The Five Central Psychological Challenges Facing Effective Mobile Learning. British Journal of Educational Technology, 43, 820-832.

Wikipedia (2012) Blended Learning. http://wikipedia.org/wiki/Blended_learning 
Scientific Research Publishing (SCIRP) is one of the largest Open Access journal publishers. It is currently publishing more than 200 open access, online, peer-reviewed journals covering a wide range of academic disciplines. SCIRP serves the worldwide academic communities and contributes to the progress and application of science with its publication.

Other selected journals from SCIRP are listed as below. Submit your manuscript to us via either submit@scirp.org or Online Submission Portal.
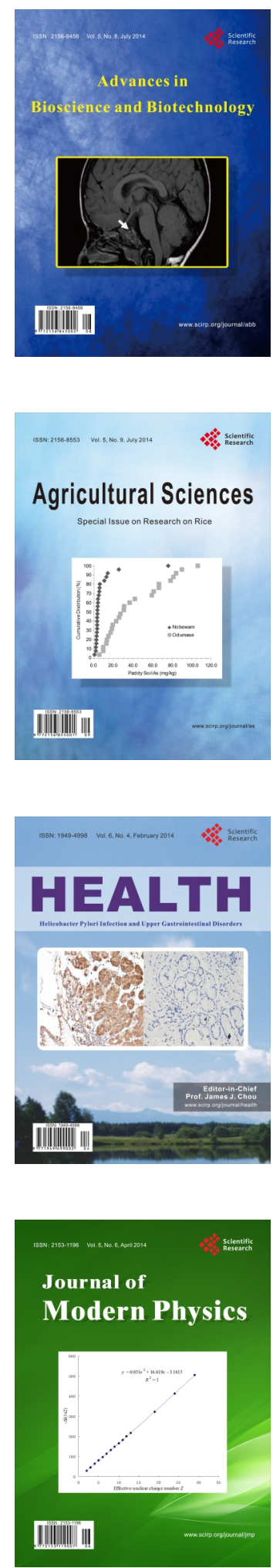
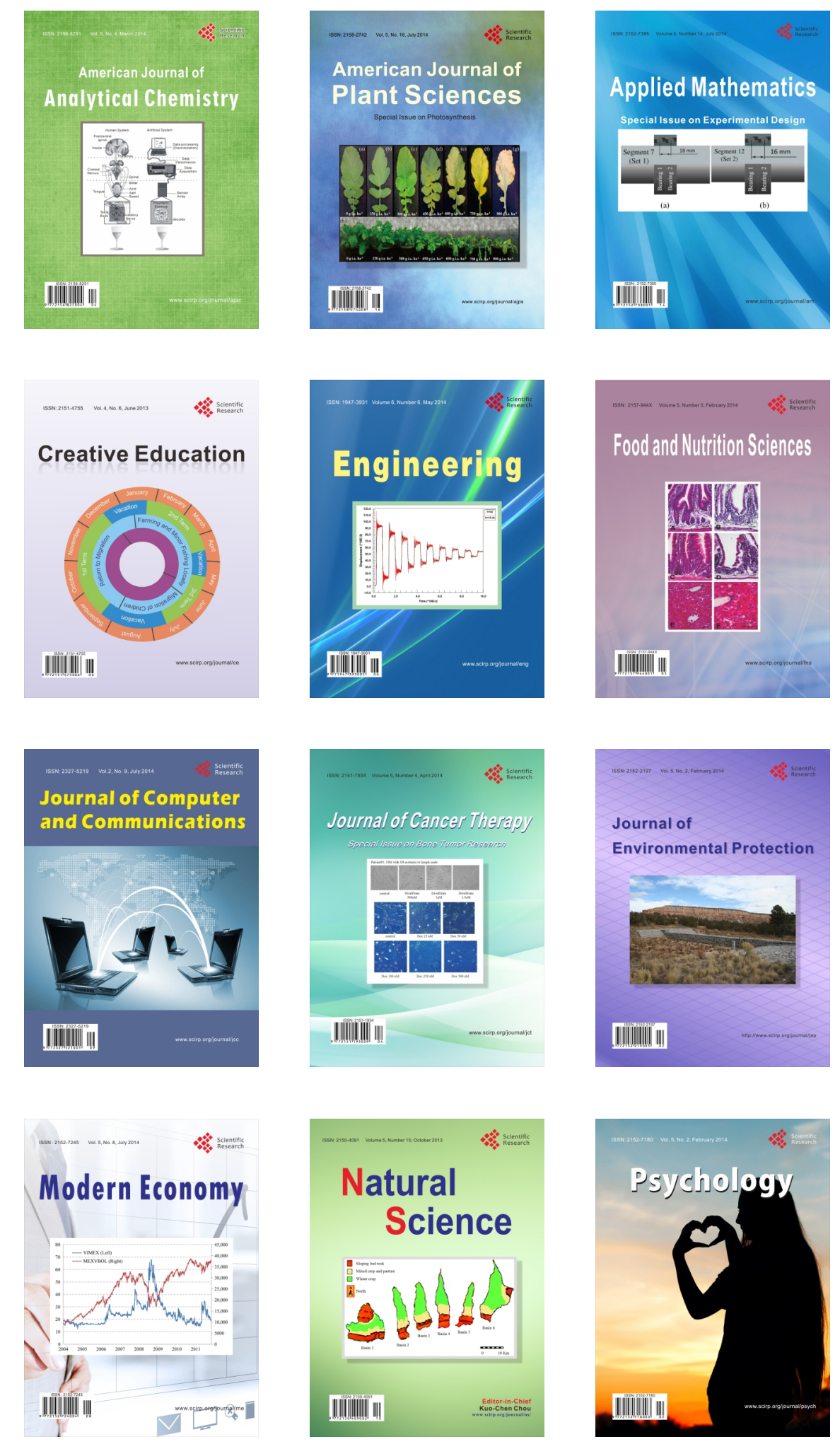